\title{
Flow-driven soil erosion processes and the size selectivity of sediment
}

H. Asadi ${ }^{a^{*}}$, A. Moussavi ${ }^{\mathrm{a}}$, H. Ghadiri ${ }^{\mathrm{b}}$, C.W. Rose ${ }^{\mathrm{b}}$

${ }^{a}$ Faculty of Agricultural Sciences, University of Guilan, Rasht 41635-1314, Iran

${ }^{\mathrm{b}}$ Faculty of Environmental Sciences, Environmental Future Centre, Griffith University, Nathan, Queensland 4111, Australia

* Corresponding author: Soil Science Department, Faculty of Agricultural Sciences, University of Guilan, Rasht, P.O. Box 41635-1314, Iran. Tel: +98 131 6690388, Fax: +98 131 6690281, Email: asadi@guilan.ac.ir 


\title{
Flow-driven soil erosion processes and the size selectivity of sediment
}

\author{
H. Asadi, A. Moussavi, H. Ghadiri, C.W. Rose
}

\begin{abstract}
The processes and mechanisms of entrainment and transportation of soil particles by surface runoff was investigated in the laboratory by a $0.05 \times 0.2 \times 3 \mathrm{~m}$ flume for two contrasting soil samples. The results show that there are at least two different mechanisms affecting particle transport by flow, with their relative importance relating to hydraulic condition, especially flow streampower. Different particle size classes are transported mainly by one mechanism. Suspension/saltation was observed to be the only mechanism at low streampowers $\left(<0.1 \mathrm{~W} \mathrm{~m}^{-2}\right)$. Bed load transport, probably involving rolling was shown to be activated at the streampowers greater than a specific threshold of about 0.1-0.15 $\mathrm{W} \mathrm{m}^{-2}$, becoming the dominant transport mechanism at these modest streampowers. The relative importance of the two transport mechanisms was also related to soil types. Particle density seemed to have a main role in this context. Comparison with theoretical prediction of sediment concentration provided some support for the increasing dominance of bedload transport mechanisms with increasing streampower in these experiments.
\end{abstract}

Keywords: Suspension-saltation; Rolling; Streampower; Density; Aggregate

\section{Introduction}

Previous studies have shown that in soil erosion due to steady overland flow there are dynamic changes in sediment characteristics, especially its size distribution (e.g. Asadi et al., 2007b; Baigorria and Romero, 2007; Rose et al., 2007). Related changes also occur under rainfall erosion (e.g. Hairsine et al., 1999; Hogarth et al., 2004). A better understanding of the dynamics of the sediment size distribution will improve understanding of erosion and sedimentation processes, and consequently improve erosion modeling. It can also provide the basis for understanding of the transfer of nutrients and 
pollutants from agricultural and range lands to waterways, and the ability to better model these fluxes (Tromp-van Meerveld et al., 2008).

It has been reported that interrill soil erosion processes are size-selective (Asadi et al., 2007a, b; Gabriels and Moldenhauer, 1978; Hairsine et al., 1999; Hogarth et al., 2004; Loch and Donnollan, 1982; Malam Issa et al., 2006; Meyer et al., 1980; Miller and Baharuddin, 1987; Mitchell et al., 1980; Proffitt et al., 1991; Romero et al., 2007; Slattery and Burt, 1997; Sutherland et al., 1996; Wan and El-Swaify, 1998). The general agreement is that eroding sediment is enriched in clay and silt-sized particles relative to the original soil in the commencement of the erosion event and gradually becomes coarser, becoming very similar to that of the original soil at final steady state condition. However, in some cases it has been observed that the sediment size distribution is bimodal during the erosion event, especially for flow- driven erosion (Asadi et al., 2007b).

Under flow-driven erosion at low streampowers, Asadi et al. (2007b) found that the size of sediment is distributed as a bimodal type of mass fraction. They concluded that this characteristic behavior did not result from the size distribution of the original soil, nor is it all likely to have been the result of aggregate breakdown during erosion. It was concluded that the bimodal distribution of the sediment resulted from two different transport mechanisms of suspension/saltation and rolling, acting dominantly on particles of different size classes (Asadi et al., 2007b).

Approximate (Rose et al., 2007) and analytic (Tromp-van Meerveld et al., 2008) solutions to Hairsine-Rose theory (Hairsine and Rose, 1991, 1992a, b) for flow and rainfall erosion respectively, have shown some differences between the observed and predicted size distribution of sediment. The presence of rolling in conjunction with or parallel to saltation, the only mechanism assumed in the theory, was mentioned as a possible reason for such differences (Rose et al., 2007).

A hypothesis to explain previous experimental results which showed a bimodal distribution for sediment size (Asadi et al., 2007b) was that there may be some threshold in streampower which needs to be exceeded for rolling transport to occur for medium to larger sized sediment particles or aggregates. In the reported experiments the experimental conditions investigated by Asadi et al. (2007b) have been extended to 
somewhat higher streampowers, and furthermore the effect of particle density on transport mechanisms has been investigated.

\section{Materials and methods}

Two contrasting soil materials were used in the study to provide particles with different densities. The first soil was a well-aggregated forest soil with mean weight diameter of aggregates $(<4 \mathrm{~mm})$ of $1.69 \mathrm{~mm}$, and the second was a non-cohesive fluvial sand. The forest soil has a clayey texture containing 5.25 and 2.75 percent organic matter and equivalent calcium carbonate, respectively. Though particle density was assumed to be $2,650 \mathrm{~kg} \mathrm{~m}^{-3}$ for fluvial sand particles, it was $1,760 \mathrm{~kg} \mathrm{~m}^{-3}$ on average for forest soil particles (aggregates) measured by the method of Chepil (1950). Secondary particle (aggregate) size distribution (denoted PSD) of the two samples as measured by wet sieving was almost similar (Fig. 1). The main difference of particle size distribution (PSD) between the two samples is related to the maximum size which was chosen arbitrarily. While the forest soil was passed through a $4 \mathrm{~mm}$ sieve, the fluvial sand was passed through a $2.36 \mathrm{~mm}$ sieve. A pre-test experiment showed no particle movement under shallow flows used in this study for fluvial sand which had passed through a $4 \mathrm{~mm}$ sieve.

\section{INSERT FIGURE 1 ABOUT HERE}

A solid base tilting flume with runon facility was used to carry out the experiments (Fig. 2a). In all the reported experiments, flow was provided at the top of the flume at a constant rate. After a set of pre-test experiments, to carry out experiments in a wider range of hydraulic conditions the width of the flume was reduced to $5 \mathrm{~cm}$ (Fig. 2b) to avoid rilling and maintain an uniform flow during the experiment. A uniform bed with 5 $\mathrm{cm}$ depth of each sample was formed before being saturated for one night with tap water. The study was performed during 2009 at the soil erosion research laboratory of Guilan University.

\section{INSERT FIGURE 2 ABOUT HERE}

Seven experiments were carried out on the forest soil and eight on the fluvial sand. Flow streampower ranged from 0.05 to 0.47 and 0.08 to $0.49 \mathrm{~W} \mathrm{~m}^{-2}$ for forest soil and sand, respectively. Also, the range of flow depth was 4 to 14 and 4 to $24 \mathrm{~mm}$ for forest soil and sand, respectively. Hereafter the experiments on the forest soil will be denoted 
by F1 to F7 and those on the sand by S1 to S8. The details of the experiments including slope steepness and flow rates are given in Table 1. Experiment duration was 20 min.

Flow streampower $(\Omega)$ was calculated by:

$$
\Omega=\rho g S q \quad\left(\mathrm{~W} \mathrm{~m}^{-2}\right)
$$

where $\rho$ is the density of the fluid, g is gravitational acceleration, $\mathrm{S}$ is slope angle of flume bed, and $\mathrm{q}$ is the volumetric flux per unit width.

Runoff was periodically sampled to yield measurement of sediment concentration and the aggregate size distribution of eroded sediment leaving the flume during the experiments. Eight 200-400 mL samples were collected for determining sediment concentration and four 2-5 litre samples were taken at 1, 5, 10 and 20 minutes from the commencement of the experiment for PSD analysis. The nest of sieves used in wet sieving were of size 2.0, 1.0, 0.5, 0.25, 0.125, 0.075 and $0.044 \mathrm{~mm}$. Wet sieving was commenced with fast wetting (immersion wetting) for original soil samples, and within $48 \mathrm{~h}$ of the experiment for sediment samples. The duration of sieving for every sample was $10 \mathrm{~min}$ at a frequency of 40 RPM.

Using the wet sieving data, each of the original un-eroded materials, [i.e. forest soil $(<4 \mathrm{~mm})$ and fluvial sand $(<2.36 \mathrm{~mm})$ ], were subdivided into I=20 size classes, each having an equal mass fraction. The fraction of each of I size classes in the outflow sediment at different times of each experiment was then obtained using the subdivision of equal classes obtained for the original soils as described in Asadi et al. (2007a).

\section{Results and discussion}

Changes with time in the measured sediment concentration at the exit from the flume are given in Figure 3(a) and (b) for the forest soil and fluvial sand. Sediment concentration was high at the start of the experiments but decreased and approached an approximately constant value. As shown in Figure 3, time of approach to an approximately constant value was shorter for the forest soil than the fluvial sand, and for lower flow rates and slopes than for higher flow rates and slopes.

INSERT FIGURE 3 ABOUT HERE 
Fig. 4a-g shows the mass fractions of each of the 20 size classes in the outflow at four different times for the experiments (F1-F7) on the forest soil. Results for times 1, 5, 10 and 20 minutes are given in the order left to right for each size range. The original uneroded soil consisted of 5 equal mass fractions in each size class, indicated in Fig. 4 by a uniform original fraction of $5 \%$. Eroded sediment fractions greater than $5 \%$ can be said to be preferentially transported (Fig. 4). As shown in Table 1, bed slope increased gradually from experiment F1 to experiment F7, and with different flow rates, flow streampower increased from $0.057 \mathrm{~W} \mathrm{~m}^{-2}$ to $0.47 \mathrm{~W} \mathrm{~m}^{-2}$, though not in an absolutely regular manner.

Fig. 4 shows that the sediment size distribution is highest at the finest class of 0.03 mm. This class includes more than $50 \%$ of the total sediment loss for all sampling times for F1 and F3, and more than $20 \%$ for F2. The fraction of other size classes decreases gradually with size. The dominant transport mechanism would be suspention-saltation in these three experiments in which transport rate decreases uniformly with size due to increasing weight and so settling velocity of the particles (Haisine and Rose, 1992a, b; Rose et al., 2007). Experiment F4 (Fig. 4d) can be regarded as a transition from the previous condition to a new condition in which the sediment size distribution tends to be somewhat more uniform for the 20 size classes. It seems that in this F4 experiment, with a flow streampower of about $0.16 \mathrm{~W} \mathrm{~m}^{-2}$, another transport mechanism is activated affecting coarser size classes. This mechanism would be bed load transport by rolling (Asadi et al., 2007b). For the last three experiments (F5, F6 and F7), Fig. 4e-g shows a bimodal sediment size distribution, especially for the first sampling times of 1 minute. It is suggested that in this condition, suspention-saltation is responsible for the first peak at the finest class, and bed load transport is responsible for the second peak at the coarser classes. In most of the experiments, rolling of particles was observed, especially coarse sands and large aggregates.

\section{INSERT FIGURE 4 ABOUT HERE}

Fig. 5a-h shows the mass fractions of each of the 20 size classes in the outflow at different times for the experiments (S1-S8) on the fluvial sand. Results for different times of 1, 5 and 10 minutes in Fig. 5a and Fig. 5b, and 1, 5, 10 and 20 minutes in Fig. 5c-h are given in the order left to right. As shown in Table 1, flow rate and bed slope increase 
gradually from experiment S1 to experiment S8. Flow streampower consequently increases from $0.037 \mathrm{~W} \mathrm{~m}^{-2}$ to $0.494 \mathrm{~W} \mathrm{~m}^{-2}$. The results are somewhat similar to those on the forest soil. For the first two experiments (S1 and S2) with a streampower less than $0.05 \mathrm{~W} \mathrm{~m}^{-2}$, there is a peak in the sediment size distribution at the finest size class $(0.085$ $\mathrm{mm})$ and a minimum at the second fine class $(0.180 \mathrm{~mm})$. All other size classes have been transported almost uniformly according to their abundance in the original bed, i.e. the fraction is around $5 \%$ which is the equal mass fractions of size classes in the original sample (Fig. 5a and 5b). Sediment size distribution becomes bimodal with increasing streampower in the next experiments, especially for the first sampling times of 1 minute (Fig. 5c-h).

Results for the fluvial sand exhibit two major differences with the forest soil in respect to particle size distribution of sediment (Fig. 4 and 5). The first difference refers to the sizes of finest and coarsest size classes which are 0.085 and $2.18 \mathrm{~mm}$, respectively for fluvial sand against 0.03 and $3.00 \mathrm{~mm}$, respectively for forest soil. The second difference relates to particle density, while all particles of fluvial sand have a particle density of about $2,650 \mathrm{~kg} \mathrm{~m}^{-3}$, particle density was $1,760 \mathrm{~kg} \mathrm{~m}^{-3}$ on average for forest soil particles (aggregates) as mentioned in the Materials and Methods. These differences have caused: (i) transport percentage of the finest size class, i.e. first peak to be lower for the fluvial sand than the forest soil, (ii) transport percentage of the coarser size classes, shown in the second peak to be higher for the fluvial sand than the forest soil, and (iii) the lowest sediment concentration to be for size classes between $0.18-0.38 \mathrm{~mm}$ in fluvial sand, while it occurred for $0.5-1.0 \mathrm{~mm}$ size classes in the case of forest soil. It is hypothesized that this size class with lowest sediment concentration may be considered as a border between dominance by the two transport mechanisms, with saltation dominating the smaller size ranges.

There are dynamic changes in sediment PSD during any given experiment for both soils (Fig. 4 and 5). Both the fractional sediment concentration of each size class, and the size classes with minimum and maximum transport change with time. Probably the main reason for such changes is that the particle size distribution of the eroding bed is changing continuously with time. In apparent contrast with theories (Rose et al., 2007; Hairsine and Rose, 1992a, b) and previous observation (Beuselinck et al., 1999; Hogarth et al., 2004; 
Proffitt and Rose, 1991), sediment size distribution did not become the same as that of the original soil at the end of the experiment. However, as shown in Fig. 3, change was still occurring at this time (20 minutes) for some of the experiments (especially on fluvial sand), so equilibrium may not have been reached for those experiments. The theory of Hairsine and Rose (1992a) also implies that change in settling velocity distribution can persist for substantial times.

\section{INSERT FIGURE 5 ABOUT HERE}

The PSD of the eroding bed is shown to change continuously with time from the initial situation of equality in mass fraction of the size classes (Asadi et al., 2007b). Accordingly discussion is focused on the first sampling time of 1 minute, and the cumulative particle size distributions of outflow sediment at this sampling time are presented in figure 6 for both soil types. Outflow sediment has a very fine distribution for the experiments with low streampower on forest soil (Fig. 6a), with more than $80 \%$ of the sediment in F1 consisting of particles finer than $0.044 \mathrm{~mm}$. Sediment size distribution becomes coarser with increasing flow streampower, finally becoming similar to or even coarser than that of the original soil. In the case of fluvial sand (Fig. 6b), while sediment PSD is finer than the original soil under low streampowers, it clearly becomes coarser than the original soil as streampower increases. The differences in behavior between the two soils may be due to the differences in size, density and shape of particles.

\section{INSERT FIGURE 6 ABOUT HERE}

To clarify understanding of processes, the individual mass fractions of each of the 20 size classes in the outflow at sampling time of 1 minute for four selected experiments (F1, F4, F5 and F6) have been redrawn for forest soil (Fig. 7), and for four selected experiments (S2, S4, S6, and S7) with fluvial sand (Fig. 8). For both soils these figures present data in order of increasing streampower.

Figure 7 shows that for forest soil, the finest size class forms a considerable fraction of outflow sediment in the experiment with lowest streampower (F1, Fig 7a) and the fractional sediment decreases with size for next three size classes, and remains very low and somewhat uniform for larger size classes. Sediment size distribution becomes initially bimodal (Fig. 7b), then tends toward uniform (Fig. 7c), and finally again becomes more clearly bimodal (Fig. 7d) with increasing streampower. While the finest 
size class of $0.03 \mathrm{~mm}$ is always high, the size classes with the lowest concentration and the higher secondary peak in concentration differ depending on the hydraulic condition of the experiment (i.e. on flow rate and slope). Both the minimum and second maximum concentrations of sediment in the PSD move to coarser size classes with increasing streampower. For fluvial sand, Fig. 8 also shows that how the minimum and second peak fractions in the sediment PSD change with flow streampower for the selected experiments of S2, S4, S6, and S7.

\section{INSERT FIGURES 7 and 8 ABOUT HERE}

Table 2 summarizes the information on the changing size classes with lowest sediment transport and second peak for selected experiments on both samples at a time of 1 minute. It is hypothesised that the size classes with lowest transport rate provide a border between the two transport mechanisms (suspension-saltation and rolling), with this border increasing in sediment size with increasing streampower. If so, this implies that the upper size limit of particles transported by suspension-saltation increases with streampower.

Based on the hypothesis that size class with minimum transport rate is an approximate border between suspension-saltation and bed load transport, the relative importance of each mechanism in sediment loss can be calculated. Table 3 presents the relative importance of suspension-saltation and bed load transport at sampling time of 1 minute for all experiments carried out on both samples, based on the minimum in transport hypothesis. Table 3 shows that for the forest soil, suspension-saltation mechanism has an important role in particle transport, but a lower importance in the case of fluvial sand is indicated, especially at higher streampowers when bed load transport by rolling becomes dominant.

Table 3 shows that for forest soil about 80 percent of soil particles has been transported by suspension-saltation in experiments with low flow rate, slope and consequently low streampower (i.e. F1 and F3), however the importance of this mechanism decreases to about 40 percent in the experiments with high flow rate and slope (i.e. F6 and F7). There is a strong relationship (Fig. 9a) between the relative effect of suspension-saltation in sediment transport and streampower if the data for experiment F5 is ignored. In the case of fluvial sand (Fig. 9b), though the importance of suspensionsaltation reduces with streampower (the exception being S6), sediment transport by this 
mechanism is generally lower than 30 percent, and remains between 5-10 percent when streampower exceeds about $0.1 \mathrm{~W} \mathrm{~m}^{-2}$ (Table 1, Fig 9b). The main reason for this difference between the two samples may be due to different particle densities and so settling velocities. No explanation is available on why data for experiments F5 and S6 seem to be outliers in Fig. 9.

\section{INSERT FIGURE 9 ABOUT HERE}

\section{Comparison of measured sediment concentration with theory}

The theory developed by Hairsine and Rose (1992a) for flow-driven erosion assumes saltation transport to be dominant. However earlier considerations in this paper indicate that some mechanism other than saltation (such as rolling) tends to become increasingly important or dominant with increase in streampower of the flow. This indication was further tested by calculating the equilibrium (or steady-state) sediment concentration at the transport limit $\left(c_{t}\right)$, on the assumption that soil strength in the reported experiments was negligibly small. From Hairsine and Rose (1992a):

$$
c_{t}=\frac{F\left(\Omega-\Omega_{0}\right)}{v_{a v} g D}\left(\frac{\sigma}{\sigma-\rho}\right) \quad\left(\mathrm{kg} \mathrm{m}^{-3}\right)
$$

where the value of $\mathrm{F}$ has been generally found to be approximately $0.1, \sigma$ is wet sediment density, $\rho$ is the density of the fluid (assumed equal to that of water at the modest sediment concentrations experienced), $\Omega$ is streampower with threshold value $\Omega_{o}, g=$ $9.8 \mathrm{~m} \mathrm{~s}^{-2}$, and $v_{a v}$ is the average settling velocity of the sediment.

Neglecting $\Omega_{o}$, Figs. 10a,b compare value of $c_{t}$ predicted using Eqn. (2) with measured sediment concentrations at approximate steady state condition.

\section{INSERT FIGURE 10 ABOUT HERE}

For both soils, Fig. 10 shows good agreement between measured and predicted sediment concentrations when these are lower, but increasing divergence from the 1:1 relation as sediment concentration increases. As shown by Fig. 3 and Table 1, increased sediment concentration does not always correspond to an increse in streampower, so the increased divergence shown in Fig. 10 does not always correspond to increased streampowers. 
Saltation/suspension would be expected to be a more efficient transport mechanism than bedload transport mechanisms such as rolling or mass movement. Thus if, as indicated by Table 3, bedload transport becomes a more important mechanism at higher streampowers, then a corresponding increased overprediction of sediment concentration by Eqn. (2) would be expected, as has been shown to occur (Fig. 10). Despite uncertainty in the experimental relationship between sediment concentration and streampower, the general nature of the divergence from the 1:1 relationship shown in both Figs. 10a and 10b does provide some support for the hypothesis presented in interpreting the experimental data of Figs. 4, 5, 7, and 8.

\section{Conclusion}

Dynamic changes in sediment size distribution were measured for two contrasting soil samples under flow-driven erosion at a range of low to modest streampowers. The results suggest that suspension/saltation is the only erosion mechanism at work for both samples at very low streampower, affecting mainly very fine to fine particles. However, with increasing streampower the observed sediment PSD's indicate that some mechanism in addition to suspension/saltation is gradually activated, enhancing the transport of medium to larger sized sediment particles or aggregates. Such enhancement requires a threshold streampower to be exceeded, when bedload transport by rolling was observed to occur. The relative importance of the two types of sediment transport mechanisms was related to streampower and soil type. While the relative importance of suspension/saltation reduced with increasing streampower for both soil types, rolling became more important at modest streampowers for the forest soil. In the case of fluvial sand, suspension/saltation was always less importance, being less than 30 percent, and becomes less important with increasing streampower.

Sediment concentration predicted using theory which assumed the dominance of saltation/suspension was compared with measured concentration. This comparison provided some support for the hypothesis of increase in bedload transport with streampower suggested by the reported experiments.

\section{Acknowledgment}


Funding for this research from the University of Guilan is gratefully acknowledged.

\section{References}

Asadi, H., Ghadiri, H., Rose, C.W., Rouhipour, H., 2007a. Interrill soil erosion processes and their interaction on low slopes. Earth Surf. Process. Landforms 32, 711-724. doi:10.1002/esp.1426.

Asadi, H., Ghadiri, H., Rose, C.W., Yu, B., Hussein, J., 2007b. An investigation of flow-driven soil erosion processes at low stream powers. J. Hydrol. 342, 134-142.

Baigorria, G.A., Romero, C.C., 2007. Assessment of erosion hotspot in a watershed: integrating the WEPP model and GIS in a case study in the Peruvian Andes. Environ. Model. Soft., 22, 1175-1183. doi:10.1016/j.envsoft.2006.06.012.

Beuselinck, L., Govers, G., Steegen, A., Quine, T.A., 1999. Sediment transport by overland flow over an area of net deposition. Hydrol. Process. 13 (17), 2769-2782.

Chepil, W.S., 1950. Methods of estimating apparent density of discrete soil grains and aggregates. Soil Sci. 70, 351-362.

Gabriels, D., Moldenhauer, W.C., 1978. Size distribution of eroded material from simulated rainfall: Effect over a range of texture. Soil Sci. Soc. Am. J., 42, 954-958.

Hairsine, P.B., Rose, C.W., 1991. Rainfall detachment and deposition: Sediment transport in the absence of flow-driven processes. Soil Sci. Soc. Am. J. 55, 320-324.

Hairsine, P.B., Rose, C.W., 1992a. Modeling water erosion due to overland flow using physical principles, I. Sheet flow. Water Resour. Res. 28 (1), 237-243.

Hairsine, P.B., Rose, C.W., 1992b. Modeling water erosion due to overland flow using physical principles, II- Rill flow. Water Resour. Res. 28 (1), 245-250.

Hairsine, P.B., Sander, G.C., Rose, C.W., Parlange, J.Y., Hogarth, W.L., Lisle, I., Rouhipour, H., 1999. Unsteady soil erosion due to rainfall impact: A model of sediment sorting on the hillslope. J. Hydrol. 199, 115-128.

Hogarth, W.L., Rose, C.W., Parlange, J.Y., Sander, G.C., Carey, G., 2004. Soil erosion due to rainfall impact with no inflow: a numerical solution with spatial and temporal effects of sediment settling velocity characteristics. J. Hydrol. 294, 229-240.

Loch, R.J., Donnollan, T.E., 1982. Field rainfall simulator studies on two clay soils of the Darling downs, Queensland. II. Aggregate breakdown, sediment properties and soil erodibility. Austr. J. Soil Res. 21, 47-58.

Malam Issa, O., Bissonnais, Y.L., Planchon, O., Favis-Mortlock, D., Silvera, N., Wainwright, J., 2006. Soil detachment and transport on field- and laboratory-scale interrill areas: Erosion processes and the size-selectivity of eroded sediment. Earth Surf. Process. Landforms 31, 929- 939. doi:10.1002/esp.1303.

Meyer, L.D., Harmon, W.C., McDowell, L.L., 1980. Sediment size eroded from crop row sideslopes. Trans. ASAE 23, 891-898. 
Miller, W.P., Baharuddin, M.K., 1987. Particle size of inter-rill-eroded sediments from highly weathered soils. Soil Sci. Soc. Am. J. 51, 1610-1615.

Mitchell, J.K., Mostaghimi, S., Pound, M., 1980. Primary particle and aggregate size distribution of eroded soil from sequenced rainfall events. Trans. ASAE 26, 17711777.

Proffitt, A.P.B., Rose, C.W., 1991. Soil erosion processes: II. Settling velocity characteristics of eroded sediment. Austr. J. Soil Res. 29, 685-695.

Proffitt, A.P.B., Rose, C.W., Hairsine, P.B., 1991. Rainfall detachment and deposition: Experiments with low slopes and significant water depths. Soil Sci. Soc. Am. J. 55, 325-332.

Romero, C.C., Stroosnijder, L., Baigorria, G.A., 2007. Interrill and rill erodibility in the northern Andean Highlands. Catena, 70, 105-113.

doi:10.1016/j.catena.2006.07.005.

Rose, C.W., Yu, B., Ghadiri, H., Asadi, H., Parlange, J.Y., Hogarth, W.L., Hussein, J., 2007. Dynamic erosion of soil in steady sheet flow. J. Hydrol. 333, 449- 458.

Slattery, M.C., Burt, T.P., 1997. Particle size characteristics of suspended sediment in hillslope runoff and stream flow. Earth Surf. Process. Landforms 22, 705-719.

Sutherland, R.A., Wan, Y., Ziegler, A.D., Lee, C.T., El-Swaify, S.A., 1996. Splash and wash dynamics: An experimental investigation using an Oxisol. Geoderma 69, 85-103. doi:10.1016/0016-7061(95)00053-4.

Tromp-van Meerveld, H.J., Parlange, J.Y., Barry, D.A., Tromp, M.F., Sander, G.C., Walter, M.T., Parlange M.B., 2008. Influence of sediment settling velocity on mechanistic soil erosion modeling. Water Resour. Res. 44, W06401, doi:10.1029/2007WR006361.

Wan, Y., El-Swaify, S.A., 1998. Characterizing interrill sediment size by partitioning splash and wash processes. Soil Sci. Soc. Am. J. 62, 430-437. 
Table 1 Details of the experiments carried out on the two soil types

\begin{tabular}{ccccccccc}
\hline & \multicolumn{3}{c}{ Forest soil } & & \multicolumn{3}{c}{ Fluvial sand } \\
\cline { 2 - 4 } Exp. NO. & $\begin{array}{c}\mathrm{q} \times 10^{3} \\
\left(\mathrm{~m}^{2} \mathrm{~s}^{-1}\right)\end{array}$ & $\begin{array}{c}\text { Slope } \\
(\%)\end{array}$ & $\begin{array}{c}\text { Streampower } \\
\left(\mathrm{W} \mathrm{m}^{-2}\right)\end{array}$ & Exp. NO. & $\begin{array}{c}\mathrm{q} \times 10^{3} \\
\left(\mathrm{~m}^{2} \mathrm{~s}^{-1}\right)\end{array}$ & $\begin{array}{c}\text { Slope } \\
(\%)\end{array}$ & $\begin{array}{c}\text { Streampower } \\
\left(\mathrm{W} \mathrm{m}^{-2}\right)\end{array}$ \\
\hline F1 & 0.586 & 1 & 0.0574 & $\mathrm{~S} 1$ & 0.386 & 1 & 0.0368 \\
F2 & 1.302 & 1 & 0.1276 & $\mathrm{~S} 2$ & 0.476 & 1 & 0.0466 \\
F3 & 0.404 & 1.5 & 0.0595 & $\mathrm{~S} 3$ & 1.186 & 0.7 & 0.0814 \\
F4 & 1.092 & 1.5 & 0.1606 & $\mathrm{~S} 4$ & 2.603 & 0.7 & 0.1786 \\
F5 & 0.483 & 2 & 0.0946 & $\mathrm{~S} 5$ & 0.840 & 1.5 & 0.1234 \\
F6 & 2.281 & 2 & 0.4471 & $\mathrm{~S} 6$ & 2.380 & 1.5 & 0.3498 \\
F7 & 2.402 & 2 & 0.4708 & $\mathrm{~S} 7$ & 1.901 & 2 & 0.3727 \\
& & & & $\mathrm{~S} 8$ & 2.519 & 2 & 0.4937
\end{tabular}

q, volumetric flux per unit width of plane. 
Table 2 The size classes (mm) with lowest sediment transport (LST) and second peak (SP) for selected experiments on both soils at a time of 1 minute. Experiments are listed in order of increasing streampower.

\begin{tabular}{ccccccccc}
\hline & \multicolumn{3}{c}{ Forest soil } & & & \multicolumn{3}{c}{ Fluvial sand } \\
Exp. & $\Omega$ & L.S.T. & S.P. & & Exp. & $\Omega$ & L.S.T. & S.P. \\
NO. & $\left(\mathrm{W} \mathrm{m}^{-2}\right)$ & & & NO. & $\left(\mathrm{W} \mathrm{m}^{-2}\right)$ & & \\
\hline F1 & 0.057 & $>0.375$ & - & $\mathrm{S} 2$ & 0.047 & 0.180 & - \\
F5 & 0.095 & $0.850-1.130$ & 2.405 & $\mathrm{~S} 4$ & 0.179 & 0.180 & 1.605 \\
F4 & 0.160 & $0.985-1.280$ & - & S6 & 0.350 & 0.388 & 1.605 \\
F6 & 0.447 & $1.130-1.450$ & 3.000 & S7 & 0.373 & 0.448 & 2.180 \\
\hline
\end{tabular}

$\Omega$, flow streampower. 
Table 3 Relative importance (\%) of suspension-saltation (SS) and bed load (BL) in sediment at a time of 1 minute.

\begin{tabular}{cccccc}
\hline & \multicolumn{3}{l}{ Forest soil } & & \multicolumn{2}{c}{ Fluvial sand } \\
Exp. NO. & S.S. & B.L. & Exp. NO. & S.S. & B.L. \\
\hline F1 & 80 & 20 & S1 & 27 & 63 \\
F2 & 62 & 38 & S2 & 20 & 80 \\
F3 & 83 & 17 & S3 & 6 & 94 \\
F4 & 56 & 44 & S4 & 9 & 91 \\
F5 & 34 & 66 & S5 & 5 & 95 \\
F6 & 47 & 53 & S6 & 16 & 84 \\
F7 & 42 & 58 & S7 & 7 & 93 \\
& & & S8 & 5 & 95 \\
\hline
\end{tabular}




\section{Figures Captions}

Figure 1 Secondary particle (aggregate) size distribution of the soil used in the study.

Figure 2 The flume used in the study (a), and final bed dimension in the experiments (b).

Figure 3 Changes with time in measured sediment concentration of all experiment carried out on forest soil (a), and fluvial sand (b).

Figure 4 Mass fractions of the 20 size classes in outflow sediment at four different times for the experiments carried out on the forest soil, (a) F1, (b) F2, (c) F3, (d) F4, (e) F5, (f) F6, and (g) F7. Results for sampling times of 1, 5, 10 and 20 minutes are given in the order left to right for this size range.

Figure 5 Mass fractions of the 20 size classes in outflow sediment at the different times for the experiments carried out on the fluvial sand, (a) S1, (b) S2, (c) S3, (d) S4, (e) S5, (f) S6, (g) F7, and (h) S8. Results for different sampling times are given in the order left to right.

Figure 6 Particle size distribution of outflow sediment at the time $1 \mathrm{~min}$ for the experiments carried out on the forest soil (a) and fluvial sand (b). Values in the parenthesis followed experiment number shows flow streampower.

Figure 7 Mass fractions of the 20 size classes in outflow sediment at the time 1 min for selected experiments carried out on the forest soil, (a) F1, (b) F5, (c) F4, and (d) F6. Figures are listed in order of increasing streampower.

Figure 8 Mass fractions of the 20 size classes in outflow sediment at the time 1 min for selected experiments carried out on the fluvial sand, (a) S2, (b) S4, (c) S6, and (d) S7.

Figure 9 Relationship between streampower and relative effect of suspension-saltation in sediment transport for the forest soil (a) and fluvial sand (b) at the sampling time of 1 minute from the commencement of the experiment. The outlier data in both soils (shown by a square) have been discarded from regression analysis.

Figure 10 Comparison of measured sediment concentation with that predicted using Eqn. (1) for the forest soil (a) and fluvial sand (b). 